\title{
Isan Stupas: Reflections of Value, Utilization and Cultural Heritage
}

\author{
Laddawan Mahachod $^{1}$, Boonsom Yodmalee ${ }^{1} \&$ Kosit Phaengsoi $^{1}$ \\ ${ }^{1}$ The Faculty of Cultural Science, Mahasarakham University, Khamriang Sub-District, Kantarawichai District, \\ Maha Sarakham Province, Thailand \\ Correspondence: Laddawan Mahachod, The Faculty of Cultural Science, Mahasarakham University, Khamriang \\ Sub-District, Kantarawichai District, Maha Sarakham Province 44150, Thailand. E-mail: \\ lpongsri155@gmail.com
}

Received: June 30, 2014 Accepted: July 24, 2014 Online Published: September 22, 2014

doi:10.5539/ach.v7n1p53 URL: http://dx.doi.org/10.5539/ach.v7n1p53

\begin{abstract}
Nowadays much religious architecture has been destroyed, which affects the local religious identity of Isan people. Valuable aspects of community culture have been lost, so this research aims: 1) to study the history of IsanSim and 2) to reflect on the value of utilization and cultural heritage of IsanSim. For this research, data was collected through field notes in the provinces of Mahasarakham, Kalasin and RoiEt. The research sample was selected by purposive sampling and totaled 81 individuals. Analysis was conducted by analytic induction and typological analysis. The results show that the first stage of Sim construction in Isan was influenced by LanXang culture and later incorporated architectural styles of the Rattanakosin period. This became the identity of IsanSim, as remains in the architecture of WatPhotharam, Wat Yang Thawongwararam and WatKlangKosum in Mahasarakham Province, Wat Wang NueaThamuang and Wat Sri Than in Roi Ed Province and WatUdompracharat, WatUmungkla and WatKlangKok Kho in Kalasin Province. The Sim of Isanare almost exclusively used for activities of the clergy. People in the community will promote clerical activities according to the belief that those who help to promote deeds such as kathin and especially ordination ceremonies will get great merit. The value of Sim is in their collections of community history. In addition, Sim are valuable pieces of local architecture that reflect the origins of tradition. Patterns incorporated on Simarchitecture are collaborations between various branches of local craftsmen. In addition, Sim reflect the important doctrines of Buddhism on their inner and outer walls.
\end{abstract}

Keywords: IsanSim, value, utilization, identity, belief, cultural heritage

\section{Introduction}

In Northeastern Thailand (Isan), religious buildings, such as Sim, are evidence of local prosperity. The word Sim comes from Sema or Seema, which are temple boundary markers (Phongtharanon, 2006; Kongpian, 2006). Sim in Isan are a form of inherited culture created by Isan craftsmen. They are used to host religious ceremonies and show Isan local architectural wisdom, beliefs and traditions that are related to daily life, relationships and unity.

The Buddhist Simare derived from Lao art and are small in size and short but similar to Lanna architecture, where the whole of the roof is wooden or tiled with a high, slightly curved gable. The roof decorations are on the gable apex and made from cement connected from the roof ridge or fixed to the outer gable apex. Carved wood is then mounted on top (Hengrasamee, 1987).

Surveys have found that Sim are aged about 80-100 years. Only a few remain and most are influenced by LanXang or Lao art. Much of the Isan architecture has been destroyed, largely due to a combination of age and lack of maintenance. Some Buddhist temples have been reconstructed but take a distorted form from the original models. Some temples have been demolished to make way for newer constructions, which leaves few valuable works of architecture in the locality. IsanSimhave fallen into a critical condition. At present, most remaining IsanSim are imitations from the central region of Thailand. There are a number of reasons for this but the largest is a deterioration of belief in Isan wisdom or culture and the growing popularity of Bangkok, whose art and style is perceived as more beautiful and better. This is a very dangerous concept, which could destroy the architectural heritage particular to Isan society. A knock-on effect of this is the current lack of knowledge, realization and transmission of local Buddhist faith, as well as neglect of traditional construction materials and building techniques (Jindawong, 2003). 
From the crisis and problems summarized above, the researchers were interested in conducting a study about IsanSim in the provinces of Mahasarakham, Kalasin and RoiEt to develop understanding, local pride and participation in the conservation and development of Sim.

\section{Research Methodology}

This research, IsanSim: Reflection of utilization and cultural heritage used a cultural qualitative method and was conducted with two main aims: 1) to study the history of IsanSim and 2) to reflect on the value of utilization and cultural heritage of IsanSim. A purposive sampling technique was used to identify a total of 81 randomized samples, including 27 key informants, 27 casual informants and 27 general informants. The research area covered the provinces of Mahasarakham, Kalasin and RoiEt in Northeastern Thailand.

For this research, data was collected by means of field notes, structured and non-structured interviews, participant and non-participant observation and focus group discussion. Field research began in May 2012 and was completed in September 2013. Data was validated using a triangulation technique. Analysis was conducted by analytic induction and typological analysis. The results are here presented as a descriptive analysis.

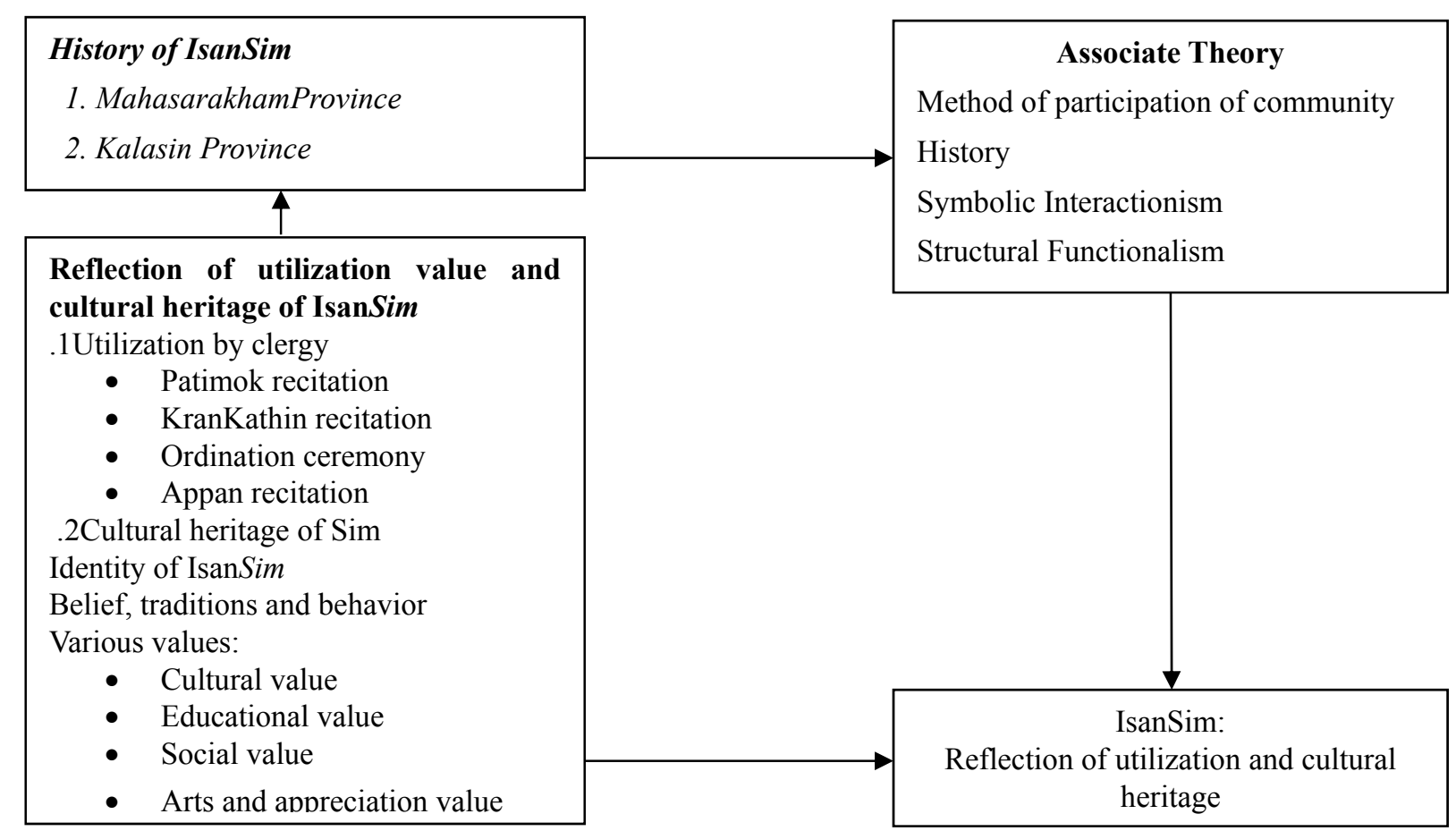

Figure 1. Conceptual research framework

\section{Results}

\subsection{History of IsanSim}

The Dvaravati period signaled the origin of Buddhism in Isan. Stone Semawere used to symbolize holy sites and were later developed into brick buildings. Evidence of this has been found at MueangFah Dad Song Yang. During the Lopburi period, Khmer religious places were constructed, such as Arokaya Sala. Later the LanXang Kingdom came to influence Isan from modern-day Laos. "The people of the LanXang Kingdom began to settle and built religious places for important rites" (Respondent A, Interview). These Sim were influenced by LanXang culture and later incorporated architectural styles of the Rattanakosin period. This became the identity of IsanSim, as remains in the architecture of WatPhotharam, Wat Yang Thawongwararam and WatKlangKosum in Mahasarakham Province, Wat Wang NueaThamuang and Wat Sri Than in Roi Ed Province and WatUdompracharat, WatUmungkla and WatKlangKok Kho in Kalasin Province (Respondent B, Interview).

\subsection{Reflection of the Utilization Value and Cultural Heritage of IsanSim}

Sim are important buildings that comprise one component of a perfect temple. The role of the Sim is in the rites of the clergy, including recitals, such as the Patimok recital. Monks of every temple must join the Patimok recital 
every fifteen days on the $15^{\text {th }}$ day of the waxing moon and the $15^{\text {th }}$ day of the waning moon in full months or the $14^{\text {th }}$ day of the waning moon otherwise. In addition, Sim are used for every morning and evening chant on normal days, with the exception of Buddhist holy days. After morning activities have been completed, the 5 o'clock morning bell will be rung and monks will congregate to begin the morning chant. A bell will also be rung in the evening to signal the evening chant. Important rites held in the Sim include ordination ceremonies, which will be set every year between the sixth month and Buddhist Lent. At the end of Buddhist Lent KarnKathin (a process of stretching out the fabric to be used to make the robes during the Kathin festival)will be organized in the temple precinct after people gave Kathin inside the Sim. During the first lunar month, Isan monks will set the Appan recital.

The Sim of Isanare almost exclusively used for activities of the clergy. People in the community will promote clerical activities according to the belief that "those who help to promote deeds such as kathin and especially ordination ceremonies will get great merit" (Respondent C, Interview). The researchers consider this very important because Buddhism is an emanation of monks. The identity of IsanSim is noticeable from their architectural components, decorations and beliefs related to Sim. Investigation found that each Sim has its own unique style. In general, every Sim will be built from cement and brick on a rectangular sitemap, facing east. The base of the Sim is shaped like an inverted and upturned lotus. Sim in the study area were found to have both Mook Na and no Mook Na. Pillars can be found throughout the inside and outside of the building, such as the Sim of WatPhotharam in Ban Dong Bung. In addition, some Sim are designed with NokMuan wooden engravings, although many have been broken and lost. RuangPhueang (Honeycomb) designs were found least and are predominantly found in Roi Et Province, notably the Sim of Wat Sri Than, where there are engraved pictures of PhanPluang Sa (Forest) and PrissanaTham (Dharma puzzle). Staircases are often designed with animal models such as the Naga at WatNuaeThaMuang or the Singha at Wat Ban Yang. Besides, "Sema are also placed in the eight compass directions around the Sim"(Respondent A, Interview).

Important characteristics that adorn the interior murals of IsanSim are the Buddha's biography, the story of Gautama Buddha, Ramasul (thunder giant), Mekala (goddess of lightning) and five gods. As for the outer walls, the story of Gautama Buddha, Buddha's biography, Sin Sai's story, PhraMalai and Nang Orapim folklore take prominent positions. Drawings often reflect the way of life of people in the community, such as farming, fishing and local traditions.

Beliefs in IsanSim concern their construction. "Sim must not be built to block the sun from the east or west" (Respondent D, Interview), which would be inauspicious. Woods used as construction materials for Sim building are Ta Kien, Teng and Rung. Only the heartwood is used because termites cannot bite it. There are no beliefs regarding other materials and these depend on local craftsmen.

\section{Conclusion}

Nowadays much religious architecture has been destroyed, which affects the local religious identity of Isan people. Valuable aspects of community culture have been lost, so this research aims: 1) to study the history of IsanSim and 2) to reflect on the value of utilization and cultural heritage of IsanSim. For this research, data was collected through field notes in the provinces of Mahasarakham, Kalasin and RoiEt. The research sample was selected by purposive sampling and totaled 81 individuals. Analysis was conducted by analytic induction and typological analysis. The results show that the first stage of Sim construction in Isan was influenced by LanXang culture and later incorporated architectural styles of the Rattanakosin period. This became the identity of IsanSim, as remains in the architecture of WatPhotharam, Wat Yang Thawongwararam and WatKlangKosum in Mahasarakham Province, Wat Wang NueaThamuang and Wat Sri Than in Roi Ed Province and WatUdompracharat, WatUmungkla and WatKlangKok Kho in Kalasin Province. The Sim of Isanare almost exclusively used for activities of the clergy. People in the community will promote clerical activities according to the belief that those who help to promote deeds such as kathin and especially ordination ceremonies will get great merit. The value of Sim is in their collections of community history. In addition, Sim are valuable pieces of local architecture that reflect the origins of tradition. Patterns incorporated on Simarchitecture are collaborations between various branches of local craftsmen. In addition, Sim reflect the important doctrines of Buddhism on their inner and outer walls.

\section{Discussion}

The study found that Sim are collections of valuable historical information about the community. Sim can be used in ordination ceremonies and important rites. Villagers will take valuables, especially money and gold, to donate to the buildings and generate merit. Sim have local architectural value that reflects both Thai-Lao and Yuan artwork. The findings correspond to the research of NongnutPhumalee (2009), which found that Sim in 
RoiEt province are closely associated with LanXangSim built by Vientiane craftsmen. They clearly reflect local culture and the simplicity of communities in Isan. Sim are valuable buildings for the locality, which help to educate new generations. The Sim is the center of the temple and all traditions of the 12 months relate to Sim. Importantly, ordination ceremonies cannot be held in any place other than the Sim. These results confirm the research of SuwitJiramanee (1990). Jiramanee proposed that if there were no Sim, there could be no ordination ceremony, meaning that Buddhism would not exist.

Sim reflect original arts and their value lies in their unique appearance. This can be noted from the components of the buildings, which are symbols to recall the virtue of the Three Jewels and represent the Lord Buddha's doctrine. This corresponds to the research of WorapanPhuwijan (2008), which discovered that the stories in murals often retell the Lord Buddha's biography, the ten incarnations of the Lord Buddha and folklore described using the Dharma. This also relates to research led by JamnongKitisakol (2010), which found that Naga often decorate the tops of Sim buildings, including parts of the roof, the walls and the staircases.

Nowadays there are fewer Sim than in the past. Important causes of the loss of Sim are natural disasters and changing social character. These lead to rapid development, affecting the degeneration of Sim. There is also corrosion and damage over time. Many Sim have been pulled down and rebuilt, so the Sim that do remain are increasingly valuable. The maintenance of remaining Sim in the right way will help to add value and ensure they remain beautiful representatives of local community culture.

AnuwatIntana (2010), found that landscape improvement, and development of archaeological sites as tourist attractions may affect the components of art, causing degeneration and damage. Sim should be conserved in harmony with traditional architectural practices and remain consistent with the natural environment. All Sim studied during this investigation were found to be located in appropriate sites, with large areas around the Sim for people to join in religious ceremonies. All Sim occurred from the combination of Thai-Lao and Yuan arts with no fixed pattern. Sim are buildings that show the purity of faith and the wisdom of local craftsmen. Importantly, Sim are important physical representations of traditional culture and Buddhist doctrine.

\section{Suggestions}

\subsection{Suggestion for Practical Implementation of the Research Results}

- The $9^{\text {th }}$ and $10^{\text {th }}$ regional offices of the Fine Arts Department should use this data to restore Sim.

- The National Office of Buddhism must use this data to instruct abbots to maintain Sim.

- The Department of Local Administration must use this data to set up a budget for maintenance and landscape improvement around Sim.

- The Secondary Educational Service Area Office 24, 26 and 27, the Primary Educational Service Area 2 and 3 of Mahasarakham Province, the Primary Educational Service Area 1 of Kalasin Province and the Primary Educational Service Area 1 of RoiEt Province must use this research to generate a local curriculum and local learning initiative.

- The Provincial Office of Tourism and Sports in all 3 provinces should use this data to publicize tourism about local archeological sites.

- The Office of Culture around Sim locations should use this data to set up a budget for the Provincial Cultural Office and Ministry of Culture to maintain Sim.

\subsection{Suggestions for Further Research}

Further research should concern:

- Other Sim in Isan, focusing on a comparison between the Simof North Isan and South Isan.

- Decorative components of Sim in the Isan region and The Lao People's Democratic Republic.

- The character of patterns of other buildings, such as relics and pavilions that stand within temple ground boundaries to further knowledge in local Isan architecture.

- The succession of artwork of local craftsmen.

- Identity of local and royal craftsmen.

\section{References}

Hengrasamee, T. (1987).Architecture in Isan.Identity Seminar of Isan Architecture [in Thai]. Bangkok: Mekapress. 
Intana, A. (2010). Study of ancient temples and new landscape management: A case study of WatDuang Dee, AmphoeMueang, Chiang Mai Province. Bangkok: Silpakorn University.

Jindawong, L. (2003). Old Cities:IsanSim Crisis. Bangkok: Chulalongkorn University Press.

Jiramanee, S. (1990).Art and Architecture of local Isan in Thai-Lao Culture.Chonburi: Burapa University.

Kitisakol, J. (2010). Naga sculpture decoration on Sim in Northern Isan.Mahasarakham: Mahasarakham University.

Kongpjan, N. (2006). Sim: Buddhist holy temples in Isan language [in Thai]. Retrieved from http://www.geocities.com/zodjang

Phongtharanon, C. (2006). Art letters from Isan: News from the locality to society [in Thai]. Retrieved from http://www.sakulthai.com

Phumalee, N. (2009) Local family of craftsmen: IsanSim in RoiEt Province. Bangkok: Silpakorn University.

Phuwijan, W. (2004). Murals of Wat Pho Chai, Baan Na Phueng, Na Hang District, Loei Province [in Thai]. Journal of research and development, 3(6), 175-185.

\section{Copyrights}

Copyright for this article is retained by the author(s), with first publication rights granted to the journal.

This is an open-access article distributed under the terms and conditions of the Creative Commons Attribution license (http://creativecommons.org/licenses/by/3.0/). 